\title{
DELINEATING PARAMETERS FOR OBJECT-BASED URBAN STRUCTURE MAPPING IN SANTIAGO DE CHILE USING QUICKBIRD DATA
}

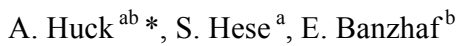 \\ ${ }^{\text {a }}$ Friedrich-Schiller University Jena, Dept. of Geography, 07737 Jena, Germany - (anica.huck, soeren.hese)@uni- \\ jena.de \\ ${ }^{\mathrm{b}}$ UFZ Helmholtz Centre for Environmental Research, Dept. of Urban and Environmental Sociology, 04318 Leipzig, \\ Germany - ellen.banzhaf@ufz.de
}

\begin{abstract}
KEY WORDS: urban structure types (UST), object-based image analysis, Quickbird data, Santiago de Chile, land use/land cover, Risk Habitat Megacity
\end{abstract}

\begin{abstract}
:
This work aims to parameterize the urban structure types (UST) in Santiago de Chile on statistical block level. In connotation of remote sensing UST are defined as land-use structure entities. Central input data for this object-oriented approach is spatially very high resolution panfused and atmospherically corrected Quickbird data. To analyse and assess the structural properties of urban landcover objects within block level entities, basic and robust land-cover class descriptions are developed. For enhanced class descriptions several image object scales are created. Based on defined UST and additional field data a set of test areas is selected for four municipalities assigned to different socio-spatial clusters in Santiago de Chile. In all test areas the distribution of the basic landcover classes is parameterized using complex sub-object and relational image object descriptions. The central features to characterise the UST in this study are percentage area and density of subscale land-cover class objects. To carry out this analysis, the expert knowledge on UST is valuable to choose specific reference objects within the statistical block level. After the concept is implemented at the smallest scale, the approach can successfully be applied to the whole municipality once specific structural information are aggregated. The work is linked to activities of the project Risk Habitat Megacity and developed in close cooperation with the Helmholtz Centre for Environmental Research - UFZ in Leipzig, Germany. Finally, the resulting land-use structure entities will be linked to socio-spatial characteristics in the above mentioned cluster with respect to urban vulnerability.
\end{abstract}

\section{INTRODUCTION}

The process of urbanisation is a global issue and examined at global, regional and local scale. To analyse the dynamics of urbanisation and their processes it is important to get deeper understanding of urban morphological processes and the physical patterns of a city. The internal structure is witness for physical and social implications.. To identify the structure of residential areas, industrial sites or open spaces are essential to comprehend the difference and identity in a city (Pacione, 2005).

The Risk Habitat Megacity project (2007 to 2011) is a research initiative, focusing on highly dynamic urban agglomerations as a space of opportunity and a space of risk (Heinrichs \& Kabisch, 2006). Santiago de Chile - the "anchor city" of this project - is characterized by a process of rapid urbanization with changes in land use and urban morphology. These changes are caused by an expansion of planned areas, a strong private real estate market, and informal housing settlements, which reduce the number of open spaces and green areas. The purpose of the land use management field of application in this project is to formulate and implement intervention strategies that will lead to the reduction of physical and social vulnerabilities.

Obtaining information about land use which concerns the management of urban and suburban regions is particularly important (Jensen \& Cowen, 1999). Furthermore, the physical structure and the composition of urban areas are key factors in urban planning issues (Netzband \& Jürgens, 2010). Looking at the numerous applications in the field of urban remote sensing, it is optimistic to assume that a single sensor can provide all the information (Gamba et al., 2005). Presently, a new generation of satellite sensors is available. The use of the high or very high resolution (VHR) images captured by these sensors allows for the improved mapping and analysis of spatial urban land use and land cover.

This paper focuses on the mapping of urban land use structure using VHR imagery. In order to approach the spatial heterogeneity of the investigation area, new methods such as object-based classification are applied.

Several studies exist which focus on the characterization of urban areas using object-based classification. Since artificial objects consist of regular shapes and are arranged in linear alignment to neighboring objects, they are not unique in the way in which non-built-up land cover objects are. In most cases, there is a correlation between certain urban structures and land use. Thus, different structure types can be distinguished by gathering information about these two spatial components. Unfortunately, there is no standardized definition of urban structure types (UST). Wickop (1999) provides the following definition: "Areas with physignomically homogeneous character, which are marked in the built-up area by characteristic formation of buildings and open spaces". Based on this definition, it is possible to distinguish spatial units which have similar environmental conditions.

A city-wide mapping of UST based on visual interpretation of color infrared aerial photographs (CIR) has been conducted in different German metropolitan regions. A few research activities have been concerned with urban structuring using advanced remote sensing techniques. Banzhaf \& Höfer (2008), Höfer et al. (2009) and Wurm et al. (2009) used object-oriented methods to derive UST from CIR and from VHR satellite images. In this work, spatial units were characterized by their land cover, land use and the type of urban fabric (Wurm et al., 2009). The results of this approach are connected to socio- 
environmental studies such as socio-spatial differentiation or socio-ecological investigation on neighbourhoods exposed to natural hazards (Netzband et al., 2009).

\section{METHODS AND ANALYSIS}

\subsection{Area of Investigation}

The Metropolitan Area of Santiago de Chile (MAS) is divided into 34 municipalities (INE 2002) with almost 6 million inhabitants (Borsdorf et al., 2006). Within this paper, four municipalities, so-called comunas, were analyzed, located in the Centre, Peri-centre, Periphery, and Eastern Peri-centre (Fig. $1)$.

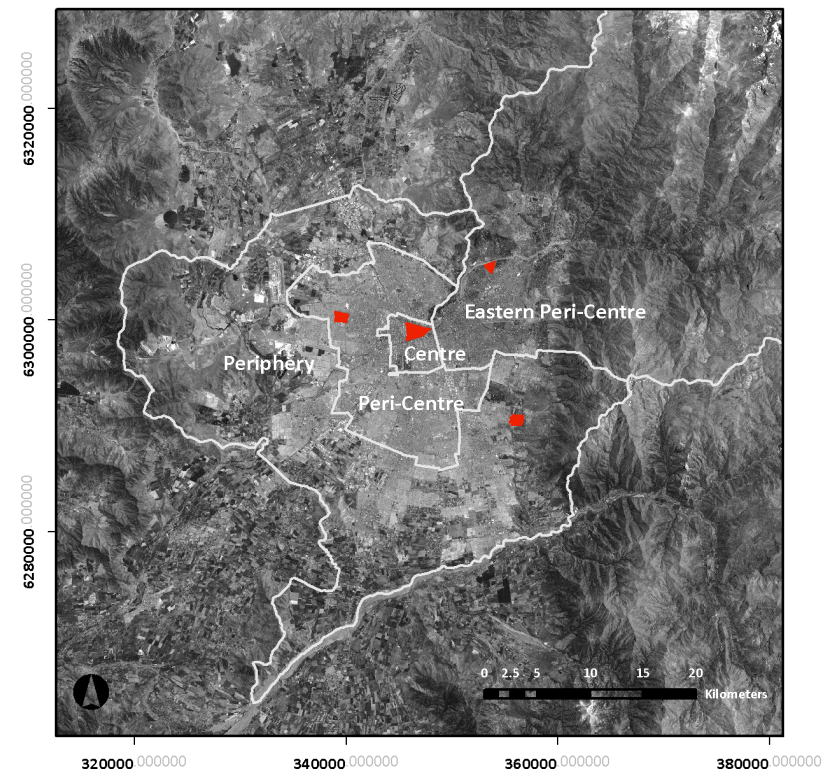

Figure 1. Location of case study within Santiago de Chile

Santiago de Chile is still affected by the spatial patterns of the past, such as urban cores built during periods of colonialization or strong polarization of urban spaces. Formerly, the differentiation in social status was heavily bound to location within the city (Borsdorf \& Hidalgo, 2009). For the last two decades, the social distance between rich (ciudad rica) and poor (ciudad pobre) has persisted, but at a different scale and distribution; thus, the spatial pattern of segregation is changing (Heineberg, 2007). Currently, many new and strict delimitation measures in small areas are replacing social exclusivity at a larger scale. Borsdorf \& Hidalgo (2009) analyzed highly segregated and protected islands within the urban neighbourhoods, which led to the physical fragmentation of the urban space.

\subsection{Satellite Data and Pre-processing}

For this analysis, Quickbird satellite imagery was used. The data for Santiago was gathered on two different dates. On the first $(2006 / 12 / 19)$, the city was recorded from north to south, and on the second (2007/01/06) from northeast to southwest (Höfer et al., 2009). The two Quickbird scenes were geometrically corrected while using a panchromatic Landsat scene (1999) as the spatial reference image. The geometric accuracy was improved by performing a geometric correction on the basis of aerial photographs from the Chilean GEOCEN institute with a geometric resolution of 2 meters. The histogram matching was calculated after the scenes were atmospherically corrected. Additionally, pansharpening was performed on the
Quickbird data. Principal Component Analysis (PCA) turned out to be the best transformation technique in this case (Ebert \& Höfer, 2009).

\subsection{Ground Reference Information}

The purpose of the field work in Santiago de Chile was the acquisition of ground reference data, for which several parameters were surveyed. After prior consultation with local experts from the Instituto de Estudios Urbanos y Territoriales (Pontificia Universidad Católica de Chile), several building blocks were selected. These statistical blocks are representative for different UST. Figure 2 describes the definition of USTs adapted to Santiago de Chile. The ones actually present within the four test sites are highlighted.

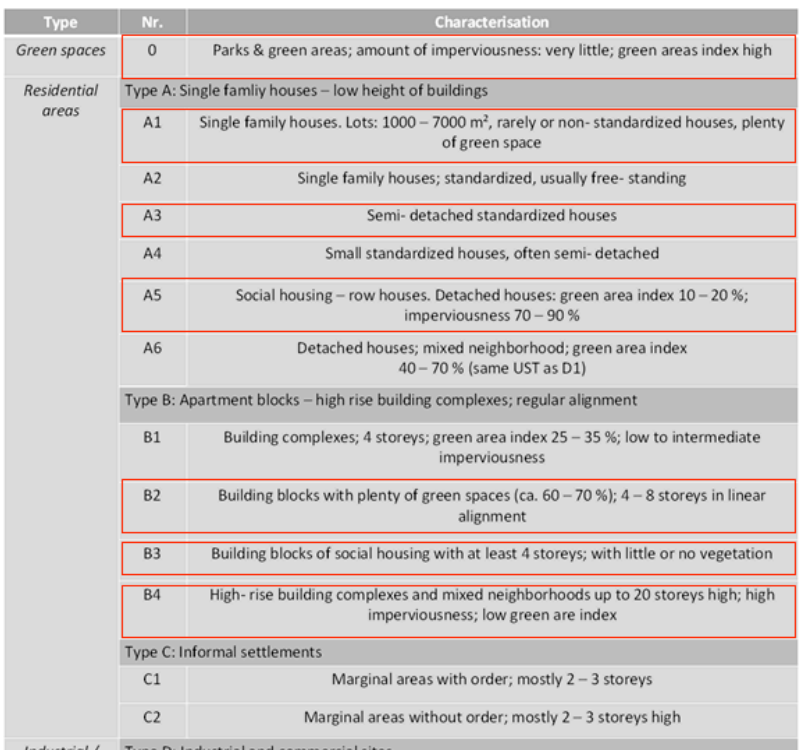

Figure 2. Outline of defined UST in Santiago de Chile (after Höfer et al., 2009)

\subsection{Classification Process}

Since this paper deals with practical applications, the major part of it is concerned with the implementation of classification methods. The results cover the structuring of the metropolitan area. The working scheme is presented in Figure 3.

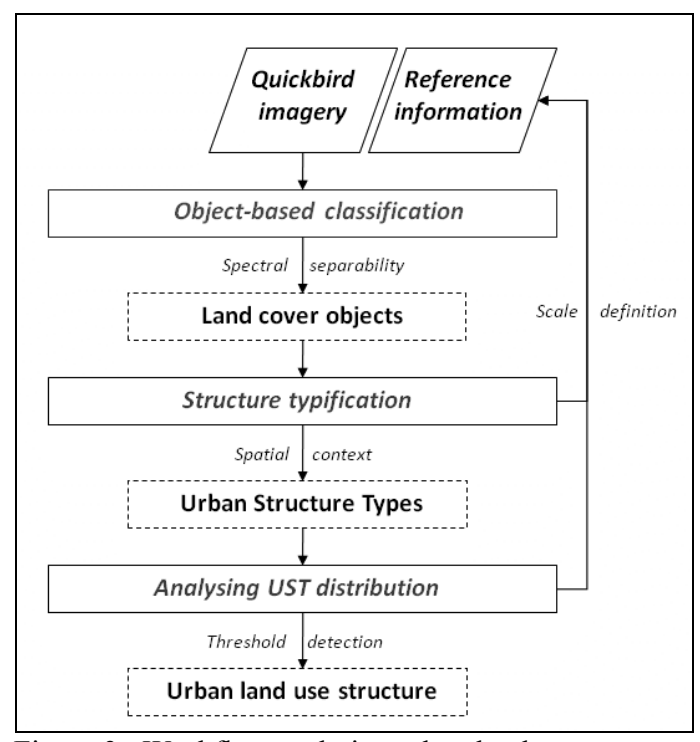

Figure 3. Workflow to derive urban land use structure 


\subsubsection{Image Segmentation:}

Single pixels do not represent real world objects. However, their mutual relationships among each other do (Taubenböck \& Roth, 2007). Using their spectral and textual characteristics, meaningful image objects can be distinguished (Herold et al., 2002). The eCognition software was employed in this study, which was successfully used for segmentation techniques in the field of remote sensing.

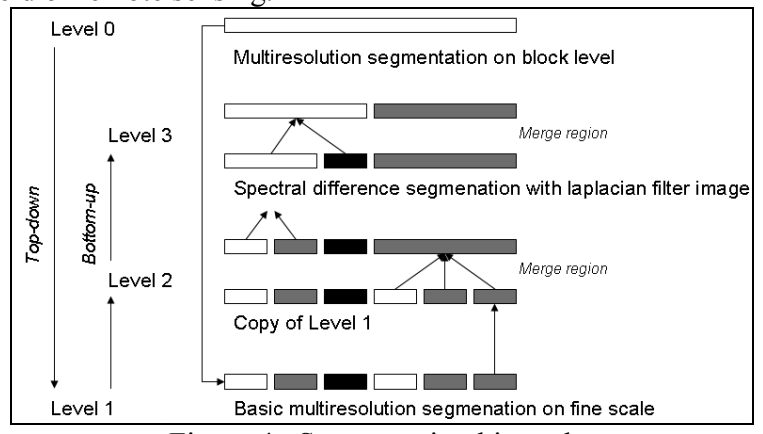

Figure 4. Segmentation hierarchy

For this study, a combination of top-down and bottom-up approaches was applied (Fig. 4). First, the highest level, Level 0 , was separated using thematic layer information of the outlined statistical blocks. During the next step, the lowest Level 1 was created, using a multi-resolution segmentation. Level 2 above was generated by copying the image objects of Level 1 (Fig. 4). Within this level, image objects were combined, using the merge region algorithm. Since this study tends to analyze UST, it is necessary to separate building structures as well as possible. Level 3 was created to separate roofs and surrounding targets. Due to the lack of height information from external data, it is more difficult to classify building objects. Roof edges are especially difficult to detect using spectral information since the target materials have similar brightness values (e.g. barren land and ceramic roofs or grey concrete and asphalt). To solve this challenge, a Laplacian filter image was included in this segmentation. The segmentation technique on Level 3 is the so-called spectral difference segmentation. For this technique, all spectral bands were used and the factor for the maximum spectral difference was set to 200. On the same level, image objects were also merged to larger entities.

\subsubsection{Classifying Land Cover Objects:}

The classification methodology is based on user-defined fuzzy class descriptions. In this study, nine land cover classes were selected: Green Areas, Barren Land, Ceramics, Metal, Concrete/Asbestos, Rivers and Creeks, Pools, Transportation Axes and Shadow. The selection of these classes is based on the results of the field work in Santiago de Chile. The most important indicators to distinguish between different UST are, besides the amount of green areas, the existence of pools and the distribution of roof materials such as ceramic roof tiles or sheet metal roofs. As mentioned before, the demarcation of grey concrete and asphalt is very difficult using multi-spectral satellite data. The class descriptions of all classes are based on spectral features or thematic information and are not derived from spatial features.

The first level contains two classes: Vegetated and Nonvegetated areas (Fig. 5). To distinguish these classes, the Normalized Difference Vegetation Index $(N D V I=(N I R-R) /$ $(\mathrm{NIR}+\mathrm{R})$ ) was applied.

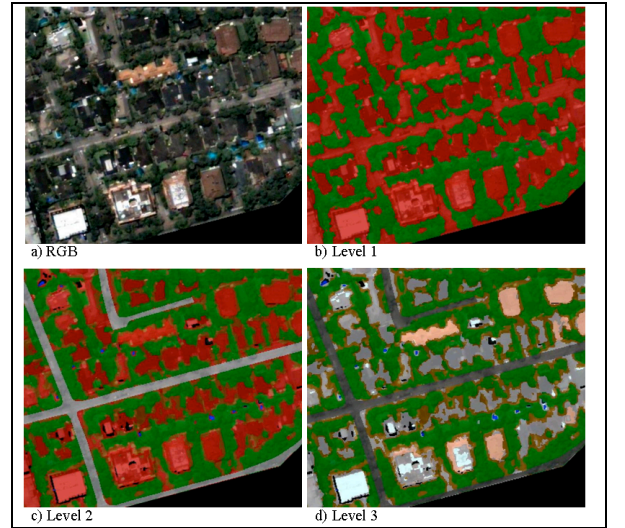

Figure 5. Land cover classification on different level

On the second level, non-vegetated areas are separated into pervious and impervious surfaces and water bodies (Fig. 5). Waterways and streets are also included, and a black body mask is created. For this procedure, pervious and impervious surface types were classified using the "blue" NDVI (bNDVI $=($ NIR Blue) / (NIR + Blue)) and the Ratio of the mean layer 3 (Ratio Layer3 = Red / Brightness). Dark objects within the scene include water and shadows. Natural as well as artificial water bodies are exclusively present in areas where no vegetation is classified. Shaded areas are only interesting in this work in relation to man-made objects and not in relation to natural targets like trees. As a consequence, a black body mask was created to separate water bodies and shadows from other land cover objects in the areas without vegetation cover. Since the brightness value of water and shadow is similar, a general black body mask was implemented using the Normalized Difference Water Index $(\mathrm{NDWI}=(\mathrm{G}-\mathrm{NIR}) /(\mathrm{G}+\mathrm{NIR}))$. Once the dark objects had been classified, it was necessary to distinguish water bodies. Chen et al. (2008) developed the so-called Spectral Shape Index (SSI $=$ ABS $(R+B-2 * G))$ for this purpose. Finally, the streets and waterways classes were classified using the feature "Thematic object attribute". The streets class only contains linear structures. This description of form characteristics means that other transportation facilities are not included, e.g. parking lots.

Level 3 contains information about different built-up materials (Fig. 5). This working step creates objects which can be associated with building complexes in the best case. As mentioned before, the spectral overlap between built-up materials is one problem when classifying single building objects. Since it is not possible to extract single buildings, a generalized approach was used. These classes cover ceramic roof tiles, sheet metal roofs, grey concrete and asphalt. The best feature to extract ceramics has been discussed above. The Ratio Layer 3 was used before to classify pervious soils. Metal shows different brightness values (channel 1) than ceramics or concrete/asbestos. Taking this information into account, the socalled Normalized Layer 1 (Normalized Layer $1=\left(\right.$ Layer $1_{\max }-$ Mean Layer1) / ( Layer $1_{\max }$ - Layer $\left.1_{\min }\right)$ ) was calculated for which it was necessary to compute statistical values.

\subsubsection{Mapping and Analysis of UST:}

Reflecting the description of the UST (Fig. 2), it is obvious that this typification involves artificial structures. Generally speaking, UST are combinations of socio-spatial parameters and environmental factors. Based on this knowledge, it is necessary to analyze the physical structure of single parcels to derive a classification hierarchy.

Having this in mind, a few samples were selected for each UST present in the four test sites. These samples represent "pure 
structures", including only parcels which were classified as such during the field work campaign. These "pure structure" entities are dominated by a single land-use type, e.g. standardized single-family houses of the middle class. Based on this selection, a separability analysis was performed. First the "Feature Space Optimization" tool in eCognition was used. Beside textural information such as area of sub-objects, density of sub-objects, asymmetry of sub-objects and direction of subobjects, were the "Relative area of sub-objects" and the "Clark Aggregation Index" employed. For the last two features, several land cover classes (Chap. 2.4.2) were used.

To create a meaningful classification hierarchy, it is necessary to include both, the results of the separability analysis and the expert knowledge. The experience gained from field work is an important factor for understanding the distribution of the features for each class and to develop an optimal classification tree. This approach is presented in Figure 6.

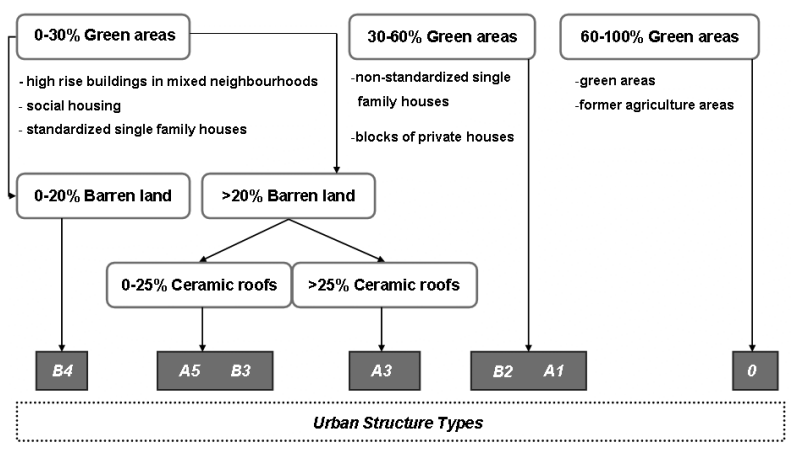

Figure 6. UST classification hierarchy

Green spaces were selected to separate certain structural classes from each other. The thresholds between the three classes were set by interpreting the results of the separability analysis. In the next step, the class " $0-30 \%$ Green Areas" was split into two sub-classes, according to the amount of barren land. The class " $0-20 \%$ Barren Land" includes the dense urban core, which is characterized by a high rate of impervious surface. In contrast to this class, "> 20\% Barren Land" contains social housing types and standardized single-family houses. After this second hierarchy level, social housing types and standardized singlefamily houses were separated by the amount of the built-up material "Ceramic" (Fig. 5-14). Beyond the characterization of these classes the amount and distribution of additional land cover objects is of great importance to compose certain structure types. Textural information is of minor importance in this study and does not show positive results.

Using this classification method, it is possible to distinguish between all UST.. Since this approach was developed for the four test sites within the municipalities and not for the entire municipalities, it is difficult to assign these classes to a whole municipality. For this, the UST had to be aggregated into more generalized classes which could also include the missing UST listed in Figure 2. To generate these Aggregated Urban Structure Types (AUST), the same three features as in Figure 6 were employed: a) Relative area of Green Areas, b) Relative area of Barren Land and c) Relative area of Ceramic. Beside this information of the percentages of these land cover classes, the "Existence of Pools" could be used as a feature to describe "exclusive residential districts with non-standardized houses".

\subsection{Classification Results}

Based on the analysis of the structural composition of the existing UST in the four test sites, the following parameters were selected to distinguish between structural entities:

a) amount of green areas, b) amount of impervious soils,

c) amount of built-up materials such as ceramics and metal,

d) distribution of built-up materials such as ceramics and metal and, e) existence of pools.

The municipality of Santiago is identical to the Centre as sociospatial cluster. The analysis shows that this section is mostly covered with high-rise buildings in mixed neighborhoods. The test site in the cluster Eastern Peri-centre is characterized by exclusive residential districts with non-standardized houses. Test sites in the other two socio-spatial clusters Peri-centre and Periphery are dominated by building complexes of social housing. While the Peri-centre is almost entirely covered with this AUST, the Periphery contains more structural categories (Fig. 7). In this area, green and former agricultural areas as well as residential districts with standardized houses for the middle class are present. This municipality is a good example of the high degree of fragmentation in Santiago de Chile. While the centre and the (Eastern) Peri-centre are still affected by the connection between social status and location within the city, the spatial distance between ciudad rica and ciudad pobre has largely disappeared in the Periphery.

For this project, an object-based accuracy assessment was performed. The geometrical accuracy could not be taken into account since there was a lack of reference information. The geometrical form of built-up objects would be particularly important to analyze. To derive the error matrices, manually selected samples were used. These test samples delineated the reference to check classification quality by comparing the classification with reference values. The accuracy assessment was performed on the following land cover classes: Ceramic, Metal, Concrete/asbestos, Green areas, Pools and Barren land. The "Transportation axis" class as well as the "Rivers and creeks" class were not included, since these classes were derived from external layer information. A total number of 180 random samples were selected, with 30 samples for each class.

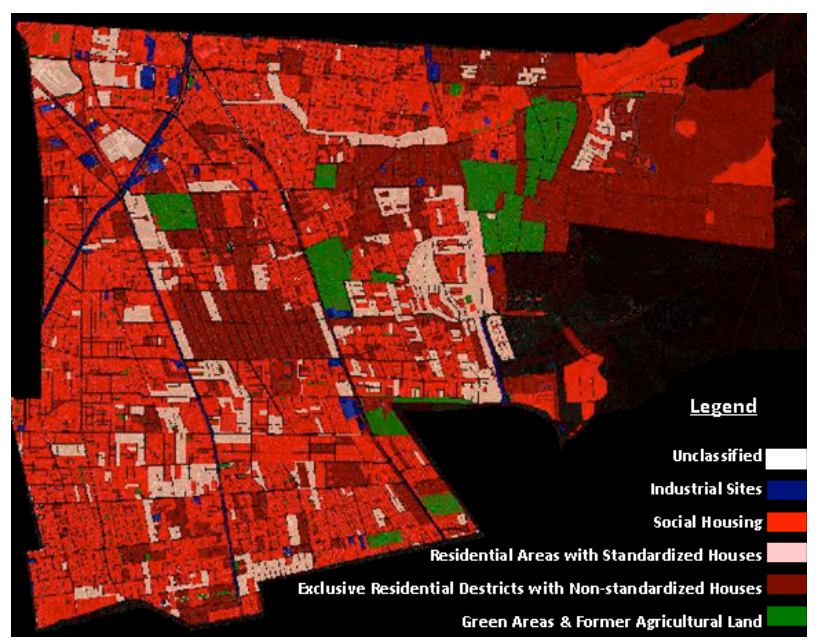

Figure 7. Municipal urban land use structure in the Periphery

The overall accuracy of the classification is $81 \%$ and the Kappa statistics show similar results with a value of 0.78 . The "Ceramic", "Metal", "Concrete/asbestos" and "Green areas" classes show positive results of the user's and producer's accuracy. Difficulties were experienced with the "Pools" and "Barren land" classes. Half of the "Pool" samples remain unclassified and result in very low producer accuracy. Looking at the "Barren land" class, confusion with the "Concrete" class can be detected. 
The five AUST were compared to 20 samples for each class. The overall accuracy had a value of $82.3 \%$ and the overall Kappa statistics had a comparable value of 0.77 . Confusion occurred between the green areas/former agricultural areas and exclusive residential districts with non-standardized houses. These classes were characterized by similar features such as good facilities (pools) and plenty of green spaces. Furthermore, residential districts with standardized houses for the middle class and social housing showed overlaps, which can be explained by the same features - the non-existence of pools and the lack of green spaces. In this particular area, the class "highrise buildings in mixed neighborhoods" refers also to industrial and commercial sites (Fig. 7), since this class only occurs in the historical centre of the city. For this reason, confusion of this AUST with other classes is difficult to understand.

\subsection{Discussion}

Looking at the results of this study, most UST described were successfully distinguished. Several classes were easily classified, but some others were mislabeled. One of the limiting factors for good results is that the outcome of the land use classification always depends on the accuracy of the land cover classification (Barnsley et al., 2001). The definition of land cover classes is based on the expert knowledge of local scientists (Pontificia Universidad Católica de Chile) as well as the knowledge gathered during fieldwork. This classification does not include all existing target materials and employs a broad-brush approach. The use of spectrometry for urban area remote sensing would be especially helpful to distinguish between built-up materials. This approach would be helpful to differentiate between specific roof and road/sidewalk types. Studying this context, the separation of concrete roof tiles and asphalt paths would be an important step towards classifying building complexes in a more appropriate way.

Another point is the inclusion of shaded areas within the land cover description. For this task, a black body mask was created to separate shaded from non-shaded areas in the non-vegetated surroundings, since the main interest is the detection of highrise and other tall buildings. Assuming that these kinds of buildings are closely connected with core shadows regardless of the time of the day, this feature was used to characterize the UST "high-rise buildings in mixed neighbourhoods". The relation between building heights and shadows should be analysed in greater detail.

In this project, the features amount and distribution of different land cover classes were discovered to be best-suited to characterize the entire range of UST in the test sites. Besides the two applied structural compositions, other measuring scales were also used. Banzhaf \& Höfer (2008) also studied the connectivity between impervious surfaces, green spaces and other open spaces to aggregate them on a neighborhood scale.

Besides the accuracy of the classified land cover objects or the analysis of the structural composition of these objects, it is useful to consider features such as building height. Wurm et al. (2009) grouped homogeneous urban areas, using building features like size, shape and height in addition to density and proportion of land cover classes. One way to extract building elevation information is to include LIDAR data. Several authors have used height information to improve the classification of urban landscapes (Zhou \& Troy, 2007; Chen et al., 2008).

The idea of the UST is based on the assumption that these units present areas of homogeneous urban morphology. Many statistical blocks include more than one single type. This problem was not approached in this study, but requires further analysis in order to derive more appropriate results. After investigating the proportion of different usages within statistical blocks, functional information should be integrated into the classification hierarchy. This kind of information refers to public buildings and service centers, shopping centers, recreational areas, hospitals, churches, cemeteries, prisons or airports. Since these areas can hardly be separated from other buildings or functional areas, they can be identified by using additional information. Banzhaf \& Höfer (2008) revert to ATKIS (Official Topographical Cartographical Information System) data to classify such functional units.

Besides validating the results with ground truth information concerning the structural composition of built-up/environmental factors, it is necessary to compare the AUST with socio-spatial data. As mentioned before, the UST can be seen as land-use entities regarding its environmental exposure as well as the usage by different socio-economic groups. The original UST which were used as the basis of this study, originated from expert knowledge concerning the coherence between the built and social environment. To analyse the relation between the AUST and socio-spatial pattern, it is very important to compare the resulting structural types with socio-economic data on a statistical block level. Krellenberg et al. (2011) successfully compared UST with educational groups in Santiago de Chile. The results showed a connection between structural compositions of the statistical blocks and the educational background of the residents. Nevertheless, the entire concept of analysing the socio-spatial distribution within the MAS at this very broad scale (4 clusters) should be seen critically. The impact of gated communities on the urban structure has been investigated by several scientists (Borsdorf et al., 2006; Bähr \& Meyer-Kriesten, 2007). Regarding these changes in the urban structure, it would be more appropriate to analyse the side-byside existence of socially higher classes and lower classes in municipalities predominantly inhabited by lower strata using the distribution and number of Urban Structure Types.

\section{CONCLUSION}

To describe the entire city area of Santiago, four test sites were selected, representing the four socio-spatial clusters of the MAS. Most of the predefined UST of the city could be located within the test sites. Ground reference information was selected during the fieldwork campaign. To assess the potential of VHR satellite data to detect different kinds of UST, two Quickbird scenes $(2006 / 2007)$ were used in this project. To derive structural categories regarding land use, it is necessary to classify spectrally distinct land cover types. The spatial pattern of these land cover objects were the key to the UST. Since urban areas are characterized by structural complexity and fragmentation of highly heterogeneous urban land cover, these spatial patterns were represented in an abstract manner, for which object-oriented algorithms were employed.

The land cover classification was based on user-defined fuzzy class descriptions, including spectral features and thematic information. The selection of these classes was based on the results of fieldwork in Santiago de Chile. The most important indicators to distinguish between different urban structures were, besides the number of green areas, the existence of pools and the distribution of roof materials such as ceramic roof tiles or sheet metal roofs. The results of the land cover classification showed good results with an accuracy of $81 \%$. The main problem at this stage of the work was the separability of barren land and built-up materials. The three distinguished target materials, a) ceramic roof tiles, b) sheet metal roofs, c) gray concrete and asphalt demonstrated spectral overlaps.

The predefined UST were distinguished by looking at the amount and distribution of land cover classes on a statistical block level. For this, the relative areas of certain classes and the 
an aggregation index were applied. Additionally, textural characteristics of single UST were observed. All present UST within the four test sites were successfully classified using these features. Nevertheless, several blocks with mixed or no usage appeared in these areas, leading to classification problems.

To transfer the resulting land use categories onto a different scale, an aggregation method was applied. More generalized UST were created to enable the classification of an entire municipality or socio-spatial cluster. These Aggregated Urban Structure Types (AUST) were characterized by the same features used to classify the UST. The results of the AUST classification were satisfactory, with an overall accuracy of $82 \%$. In this project, the AUST were only applied to the four municipalities surrounding the test sites. After looking at the number of certain AUST, as well as their distribution within the municipalities, the dominant land use structure was labelled.

Mapping urban land use structure is a key factor in the framework of analysing the structure in dynamic urban agglomerations such as carried out in Risk Habitat Megacity. Further analysis is needed in this field to describe the connection of socio-economic data with structural types on a statistical block level.

\section{REFERENCES}

Bähr, J. \& Meyer-Kriesten, K., 2007. Santiago de Chile- Eine fragmentierte Stadt?. Erdkunde, 61, pp. 258-276.

Banzhaf, E. \& Höfer, R., 2008. Monitoring Urban Structure Types as Spatial Indicators With CIR Aerial Photographs for a More Effective Urban Environmental Management. IEEE Journal of selected topics in applied earth observation and remote sensing, 1, pp. 129-138.

Barnsley, M.J., MØller-Jensen, L. \& Barr, S.L., 2001. Inferring Urban Land Use by Spatial and Structural Pattern Recognition. In: Donnay, J.-P., Barnsley, M.J. \& Longley, P.A., (eds.). Remote Sensing and Urban Analysis. GISDATA 9. Taylor \& Francis, London/ New York, pp. 115-144.

Borsdorf, A. \& Hidalgo, R. 2009. The Fragmented City Changing Patterns in Latin American Cities. The Urban Reinventors Paper Series 2005-2009. www.urbanreinventors.net (accessed 10. Sep. 2010)

Borsdorf, A., Hidalgo, R. \& Sánchez, R., 2006. A new model of urban development in Latin America: The gated communities and fenced cities in the metropolitan areas of Santiago de Chile and Valparaíso. Cities, 24, pp. 365-378.

Chen, Y., Su, W., Li, J. \& Sun, Z., 2008. Hierarchical object oriented classification using very high resolution imagery and LIDAR data over urban areas. Advances in Space Research, 43, pp. 1101-1110.

Ebert, A. \& Höfer, R., 2009. Documentation of the data preprocessing operations for the satellite images: Landsat, ASTER, Spot, Quickbird. UFZ internal document, Leipzig.

Gamba, P., Dell-Acqua, F. \& Dasarathy, B.V., 2005. Urban remote sensing using multiple data sets: past, present and future. Information Fusion, 6, pp- 319-326.

Heineberg, H., 2007. Einführung in die Anthropogeographie/ Humangeographie. 3rd edition. Ferdinand Schöningh Verlag, Paderborn.
Heinrichs, D. \& Kabisch, S., 2006. Risk Habitat Megacity. GaiA 15, pp. 157-160.

Herold, M., Roberts, D.A., Gardner, M.E. \& Dennison, P.E., 2004. Spectrometry for urban area remote sensing Development and analysis of a spectral library from 350 to 2400nm. Remote Sensing of Environment, 91, pp. 304-319.

Höfer, R., E. Banzhaf \& Ebert, A., 2009. Delineating urban structure types (UST) in a heterogeneous urban agglomeration with VHR and TerraSAR-X data. Urban Remote Sensing Joint Event, Shanghai.

INE (National Statistics Institute of Chile) 2002. Census of Population 2002.

Jensen, J.R. \& Cowen, D.C., 1999. Remote sensing of urban/ suburban infrastructure and socio-economic attributes. Photogrammetric Engineering \& Remote Sensing, 65, pp. 611622.

Krellenberg, K., Höfer, R. \& Welz, J., 2011. Relaciones y dinámicas recientes entre el uso de suelo y la composición socioeconómica en Santiago de Chile: el caso de la comuna de Peñalolén. Revista de Geografía Norte Grande.

Netzband, M., Banzhaf, E., Höfer, R. \& Hannemann, K., 2009. Identifying the Poor in Cities: How Can Remote Sensing Help to Profile Slums in Fast Growing Cities and Megacities?. IHDP Update, 1, pp. 22-28.

Netzband, M. \& Jürgens, C., 2010. Urban and Suburban Areas as a Research Topic for Remote Sensing. In: Rashed, T. \& Jürgens, C. (eds.). Remote Sensing of Urban and Suburban Areas. Dordrecht, Springer, pp. 1-9.

Pacione, M. (ed.), 2005. Urban Geography: a Global Perspective. $2^{\text {nd }}$ ed. Routledge, London \& New York.

Taubenböck, H. \& Roth, A., 2007. A transferable and stable object oriented classification approach in various urban areas and various high resolution sensors. Urban Remote Sensing Joint Event.

Wickop, E., 1999. Environmental Quality Targets as a Method for Implementing Sustainability Targets in Urban Development. In: Breuste, J., Feldmann, H. \& Uhlmann, O. (eds.). Urban Ecology. Berlin/ Heidelberg. Springer, pp. 50-54.

Wurm, M., Taubenböck, H., Roth, A. \& Dech, S., 2009. Urban structuring using multisensoral remote sensing data. Urban Remote Sensing Joint Event, Shanghai.

Zhou, W. \& Troy, A., 2007. An object-oriented approach for analysing and characterizing urban landscape at parcel level. International Journal of Remote Sensing, 29, pp. 3119-3135.

\section{ACKNOWLEDGEMENT}

The authors wish to acknowledge the following individuals for their contributions to this work: Prof. Christiane Schmullius, Dep. of Geography, FSU Jena, Germany; Dr. Sonia Reyes, Instituto de Estudios Urbanos y Territoriales, Pontificia Universidad Cátolica in Santiago, Chile. A special thanks goes to the German Academic Exchange Service (DAAD) for their financial support of the fieldwork. 